Journal of General Psychology, 1933, 42, 207-208.

LIPSITT, L. P. Simultañeous and successive discrimination learning in children. Child Development, 1961, 32, 337-347.

SHEPP, B. Role of distinctive incentives in simultaneous and successive discrimination with retardates. In D. Zeaman et al (Eds.), Learning and transfer in mental defectives. Progress Report No. 2, NIMH USPHS, 1960. Research Grant M-1099 to University of Connecticut, V. 141-151.

SMITH, J., ANDERSON, V., CUNNINGHAM, T., \& SJOBERG, W. A comparison of auditory and visual discrimination learning in retardates.
American Journal of Mental Deficiency, 1967, 72, 445-449.

ZEAMAN, D., \& HOUSE, B. J. The role of attention in retardate discrimination learning. In N. A. Ellis (Ed.), Handbook of mental deficiency, New York: McGraw-Hill, 1961

\section{NOTE}

1. The research reported in this paper was supported - by grants from the University of Connecticut Research Foundation and the U.S. Office of Education. The author is indebted to Drs. David Zeaman and Betty House in whose laboratory the research was conducted.

\title{
The effect of post-test relevant pre-tests and discussion-type feedback on learning and retention
}

\author{
S. JAY SAMUELS, University of Minnesota, \\ Minneapolis, Minn. 55455
}

The effect of posttest relevant pretest questions and discussion-type feedback on learning and retention was investigated. Ninety-six Ss were randomly assigned to one of three treatments. Experimental Group $A$ got posttest relevant pretest questions and discussion-type feedback. Experimental Group B got the same posttest relevant pretest but not discussion-type feedback. Control Group $C$ got a nonrelevant pretest and no discussion. The test of learning showed Groups $A, B$, and $C$ were all significantly different from each other. On the test of retention Group A maintained its superiority.

A major objective of teaching is to increase student achievement. One way to accomplish this goal is to improve the methodology of instruction. Although tests are usually given for the purpose of measuring student achievement and are infrequently used as an integral part of the instructional method, their use in this latter role may facilitate learning (McKeachie, 1963 , p. 1154). When a test is given as part of the teaching procedure, it may be referred to as a pretest. Pretests may be given with or without feedback and questions on the pretest may or may not be relevant to questions which will be asked on the posttest.
Kellogg \& Bryan (1938) have shown that true-false pretests given without feedback were sufficient to facilitate learning. Similarly, enhanced learning resulted from the use of adjunct questions with a written passage (Hershberger \& Terry, 1965). More recently, Rothkopf (1967) demonstrated that when pretest questions were presented before a passage was read, facilitation was specific to the concepts emphasized by the question; when pretest questions were presented after a passage was read, both question-specific and general facilitative effects were found. Furthermore, Ss who received written answers to questions did better than Ss who received no feedback. Frase (1967) has supported and extended the findings of Rothkopf (1967).

The effect of feedback on learning has been studied by Plowman \& Stroud (1942). They found that students who saw correct copies of their tests eliminated nearly $50 \%$ of their errors upon retest. In the Curtis \& Wood (1929) study, the most beneficial feedback resulted from student correction of their own papers combined with discussion of answers. Sassenrath \& Gaverick (1965) found that discussion-type feedback following an examination was superior to asking students to find answers in their books, and groups getting feedback of any variety were superior to the no-feedback group.

While a number of studies have demonstrated that pretesting and feedback enhance achievement, the effect of discussion-type feedback given in addition to a pretest has not been investigated. The pretest used in this investigation contained page references where students could find answers to the questions.

A second focus of inquiry in this investigation was to determine the effect of asking pretest questions which were directly relevant to questions asked on the posttest. In summary, then, the purpose of this study was to determine the effect of posttest relevant pretest questions and discussiontype feedback on learning and retention.

\section{SUBJECTS}

The Ss were 96 juniors enrolled in Psychological Foundations of Teaching at the University of Minnesota, Summer Session.

\section{DESIGN AND PROCEDURE}

Subjects were randomly assigned to one of three laboratory sections, with 32 to a section. Laboratory instructors and treatments were randomly assigned to sections. All 96 Ss attended the same daily lectures. Following each lecture the students went to their assigned laboratory section. The Ss were not informed that an experiment was taking place. To ensure that the groups were in fact equal, a multiple-choice examination, that was not part of the study, was given. The means for the three groups on the test were: $\quad 30.91 \quad(\mathrm{SD}=2.78), \quad 30.50$ $(\mathrm{SD}=3.23), 31.31(\mathrm{SD}=3.10)$. A one-way analysis of variance on this data showed no significant difference among the groups on this test $(F<1, d f=2 / 93$, n.s. $)$.

For the study, all the Ss were given the same reading assignment from their educational psychology textbook. They were then given in their laboratory sections a 13-item true-false pretest based upon the reading assignment. The cover sheet of the pretest contained information to the student. He was informed that the true-false test was a take-home examination, and that the score he got on the test was to be added to his other examination scores. To help the student in deciding whether his answers were correct, next to each question was a page number indicating where he could look in his textbook for the answer to the question. The students were requested to return test questions and answer sheets to lecture the following day. They were also requested to refrain from discussing their answers with fellow students. Since the pretest was to be graded, it was assumed that the students would take advantage of the opportunity to check their answers.

The treatments for the study were as follows:

EXPERIMENTAL GROUP A: POSTTEST RELEVANT PRETEST WITH DISCUSSION-TYPE FEEDBACK

This group received a 13-item true-false take-home pretest. Next to each true-false 
Table 1

Means and Standard Deviations on Posttest and Retention Test

\begin{tabular}{lcccc}
\hline & \multicolumn{2}{c}{ Posttest } & \multicolumn{2}{c}{ Retention Test } \\
& Means & SD & Means & SD \\
\hline Experimental Group A & 12.44 & $(1.14)$ & 11.78 & $(1.34)$ \\
Experimental Group B & 11.44 & $(1.57)$ & 10.84 & $(1.73)$ \\
Control Group C & 10.28 & $(2.63)$ & 9.96 & $(2.28)$ \\
\hline
\end{tabular}

question was a page reference to the textbook indicating where the student might look for the answer to the question. The 13 items on the true-false pretest were relevant to the multiple-choice items asked on the posttest; that is, the same concepts examined on the pretest were tested again on the posttest, the major difference between the two tests being the form in which the questions were asked. After the true-false pretest was returned during lecture, the laboratory instructor discussed in the laboratory section the items on the pretest. The instructor did not know what questions would be asked on the posttest.

EXPERIMENT AL GROUP B:

POSTTEST RELEVANT PRETEST, NO DISCUSSION-TYPE FEEDBACK

Experimental Group B received the same 13-item true-false take-home pretest with page references to the text as did Experimental Group A. After the pretest was returned, the laboratory instructor did not discuss with the students the pretest items but did other course-related work instead.

\section{CONTROL GROUP C: PRETEST NOT RELEVANT TO POSTTEST,NO DISCUSSION-TYPE FEEDBACK}

This group was given a 13-item true-false take-home pretest based on the readings from the textbook. Accompanying the questions were references to the text for getting answers to the questions. Although items on the pretest were related to the readings, they were not relevant to concepts tested on the posttest. There was no discussion of the pretest questions by the laboratory instructor. Instead, the instructor did other course-related work.

On the day following the return of the 13-item pretest, all the Ss were given the same 15-item multiple-choice posttest based on the assigned chapter. This multiplechoice test was a scheduled examination which was listed in the course outline. The students were given their test scores on the multiple-choice test, but there was no discussion of the test, nor were they permitted to see the examination. Two weeks later a surprise examination was given to test retention. This examination was a multiple-choice test containing 14 of the 15 items contained on the posttest.

\section{RESULTS AND DISCUSSION}

On the 13-item true-false take-home pretest with page references to where answers could be found, the group means were: 12.90 for Experimental Group A, 12.88 for Experimental Group B, and 12.91 for Control Group C. The high scores for the three groups would seem to indicate that all Ss were utilizing the page references as an aid in answering pretest questions.

The posttest, which was used to measure differences in learning among the three groups as a function of treatment manipulation, contained 15 multiple-choice items. The group means and standard deviations for learning are shown in Table 1.

According to Scheffé (1959), inequality of variances has little effect on inferences about means if the cell numbers are equal. Since in this study each treatment contains the same number of $S s$, departures from homogeneity of variance should not effect inferences on means for treatments. Planned comparisons were computed on differences between treatment means on the posttest. Results of the comparisons are shown in Table 2.

A surprise multiple-choice test containing 14 items was given to the Ss to measure retention. Means and standard deviations on retention are shown in Table 1. Planned comparisons were computed on differences between treatment means on the retention test. Results are found in Table 2.

In this investigation two questions were asked: What is the effect on performance when pretest questions cover the same concepts examined on the posttest; secondly, what is the effect on posttest performance when discussion-type feedback is based upon questions asked on the pretest.

The results indicated that asking pretest questions which are relevant to questions asked on the posttest facilitates learning,

Table 2

Planned Comparisons for Posttest and Retention Test

\begin{tabular}{lll}
\hline Comparison & Posttest & Retention Test \\
\hline A vs B & $\mathrm{t}=2.06^{*}$ & $\mathrm{t}=2.07^{*}$ \\
A vs C & $\mathrm{t}=4.45^{* *}$ & $\mathrm{t}=4.00^{* *}$ \\
B vs C & $\mathrm{t}=2.39^{*}$ & $\mathrm{t}=1.93$ \\
\hline
\end{tabular}

$*=p<.05$, two tailed; ${ }^{* *}=p<.01$, two tailed; $d f=62$.

1 The tests in this table, strictly speaking, apply to each of the three comparisons separately, not jointly. Tests which are jointly proper las regards significance levels) over all three comparisons can be made by means of the NewmanKeuls procedure. When Newman-Keuls tests were computed on these data, the results regarding significance levels were the same as those found with planned comparisons. given the conditions that the students are motivated and given help in finding answers to the pretest questions. The analysis also indicated that discussion-type feedback which focuses upon test-relevant questions also facilitates learning. However, the facilitation resulting from discussion-type feedback was of a lower magnitude than that resulting from asking posttest relevant pretest questions.

Two weeks after the posttest the retention test was administered. Only Experimental Group A, which received posttest relevant pretest questions and discussion-type feedback maintained its superiority. Experimental Group B was not significantly different from Control Group C on this test.

The variability of test scores associated with each of the treatments deserves attention. The least variability on both the posttest and retention test was found with treatments having relevant pretest questions, and the greatest variability was found with the control treatment, in which posttest relevant pretest questions were not asked. Thus, it would seem that if the educational objectives were to maximize achievement and to minimize test score variability, one way to accomplish this would be to provide a posttest relevant pretest. If, in addition, the objectives included enhanced retention, then discussion-type feedback which focuses upon the pretest questions would help to accomplish this goal.

\section{REFERENCES}

CURTIS, F. D., \& WOOD, G. A study of the relative teaching values of four common practices in correcting examination papers. School Review, 1929, 37, 615-623.

FRASE, L. T. Learning from prose material: Length of passage, knowledge of results, and position of questions. Journal of Educational Psychology, 1967, 58, 266-272.

HERSHBERGER, W. A., \& TERRY, D. F. Typographical cueing in conventional and programmed tests. Joumal of Applied Psychology, $1965,49,55-60$.

KELLOGG, W. N., \& BRYAN, P. The true-false question as an aid in studying. Joumal of Educational Psychology, 1938, 29,581-589.

McKEACHIE, W. J. Research on teaching at the college and university level. In N. L. Gage (Ed.), Handbook of research on teaching. Chicago: Rand McNally, 1963.

PLOWMAN, L., \& STROUD, J. B. Effect of informing pupils of the correctness of their responses to objective test questions. Joumal of Educational Research, 1942, 36, 16-20.

ROTHKOPF, E. Z. Learning from written instructive materials: An exploration of the control inspection behavior by test-like events. American Educational Research Journal, 1967, 3, 241-249.

SASSENRATH, J. M., \& GARVERICK, C. M. Effects of differential feedback from examinations on retention and transfer. Joumal of Educational Psychology, 1965, 56, 259-263.

SCHEFFÉ, $\mathrm{H}$. The analysis of variance. New York: Wiley, 1959, P. 345. 